\title{
REIS DO CONGO NO BRASIL, SÉCULOS XVIII E XIX*
}

\author{
Marina de Mello e Souza \\ Departamento de História - FFLCH/ USP
}

\section{Resumo}

Esse artigo busca explicar a presença de reinados negros, depois chamados de congadas, em quase todas as regiões do Brasil que receberam escravos africanos, do século XVI ao XIX. O enfoque adotado abarca Portugal, África Central e Brasil como partes integrantes de um mesmo sistema econômico, social e cultural, tecido em torno do Atlântico. A esfera da cultura e as relações de poder são os centros focais da análise, que se preocupa acima de tudo com a formação de identidades.

\section{Pallavras-Chave}

Reinados negros • Reis do Congo no Brasil • Identidade católica negra

\section{Abstract}

This article aims to explain the existence of Black kingdoms, later known as "congadas", in almost all Brazilian regions that received African slaves from the sixteenth to the nineteenth centuries. The approach places Portugal, Central Africa, and Brazil as component parts of a single economic, social and cultural system, woven around the Atlantic. Concerned primarily with the formation of identities, the analysis focuses on the cultural sphere and on power relations.

\section{Keywords}

Black kingdoms • Kings of Kongo in Brazil • Black Catholic identity

\footnotetext{
*Agradeço a Maria Helena P.T. Machado os comentários sobre esse texto.
} 
A existência de reis negros em várias sociedades coloniais das Américas é fato que à primeira vista surpreende, pois afinal estas eram sociedades escravistas, nas quais os africanos e seus descendentes, isto é, os negros, eram na maioria das vezes propriedade de seus senhores, ou seja, escravos, portanto, como podiam, em algumas situações, ser reis? E no entanto o foram, como nos contam relatos e documentos de várias qualidades que falam sobre os festejos de grupos de negros pelas ruas, em torno de seus reis e principais, ou apenas da existência de um rei, que tinha autoridade sobre aqueles que o escolhiam. Explorados principalmente por folcloristas, antropólogos e estudiosos da cultura popular, os reinados festivos nos quais grupos de negros saíam cantando, dançando e representando às ruas, vêm também ocupando alguns historiadores, principalmente aqueles interessados nas manifestações culturais brasileiras com influências africanas. No Brasil os primeiros historiadores a perceberem a sua importância foram os que pesquisaram e analisaram as irmandades de "homens pretos", como Julita Scarano em seu Escravidão e Devoção, ou os que buscaram desvendar a contribuição dos africanos para a formação das culturas brasileira e portuguesa, como José Ramos Tinhorão, em Os sons negros no Brasil e Os pretos em Portugal. ${ }^{1}$ Nos muitos estudos sobre irmandades de "homens pretos" feitos depois da pesquisa pioneira de Julita Scarano, os reis e outras autoridades a ele associadas apareceram na documentação levantada. ${ }^{2}$ Alguns autores se detiveram com mais vagar outros

\footnotetext{
${ }^{1}$ Julita Scarano, Devoção e escravidão. A Irmandade de Nossa Senhora do Rosário dos Pretos no Distrito Diamantino no século XVIII, $2^{\text {a }}$ edição, São Paulo, Companhia Editora Nacional, 1978; José Ramos Tinhorão, Os sons negros no Brasil. Cantos, danças, folguedos: origens, São Paulo, Art Editora, 1988 e Os pretos em Portugal. Uma presença silenciosa, Lisboa, Editorial Caminho, 1988.

${ }^{2}$ Alguns desses estudos são: João José Reis, A morte é uma festa. Ritos fúnebres e revolta popular no Brasil do século XIX, São Paulo, Companhia das Letras, 1991; Mary Karasch, Slave Life in Rio de Janeiro 1808-1850, Princeton, Princeton University Press, 1987; Patrícia Ann Mulvey, "The Black Lay Brotherhoods of Colonial Brazil: a history", City University of New York, Ph.D., 1976, University Microfilms International; Antonia Aparecida Quintão, Lá vem meu parente. As irmandades de pretos e pardos no Rio de Janeiro e em Pernambuco (século XVIII), São Paulo, Anablume/Fapesp, 2002; Mariza de Carvalho Soares, Devotos da Cor: identidade étnica, religiosidade e escravidão no Rio de Janeiro, século XVIII, Rio de Janeiro, Civilização Brasileira, 2000; Marcos Magalhães de Aguiar, "Vila Rica dos confrades. A sociabilidade confrarial entre negros e mulatos no século XVIII, Dissertação de mestrado, Departamento de História - FFLCH/
} 
com menos sobre as atividades ligadas a essas realezas, que atuavam principalmente por ocasião das festas dos oragos das irmandades dentro das quais esses líderes eram escolhidos.

Em livro publicado em 2002, eu mesma propus uma história da festa da coroação de rei do Congo no Brasil escravista, traçando os antecedentes das chamadas congadas. ${ }^{3}$ É aquele um estudo de cunho geral, no qual eu propus uma interpretação abrangente da presença disseminada no Brasil, do século XVII ao XIX (sem considerar o presente, pois essas festas ainda acontecem) da tradição que comunidades negras tinham de escolher um rei e outras figuras principais, que estavam à frente da realização de uma festa anual, na qual a comunidade saía às ruas festejando-nos. Além de trazer um tema mais explorado na antropologia e nos estudos de folclore para o campo da história, o meu livro também fez um esforço de entender manifestações afro-brasileiras à luz das realidades africanas, sob inspiração de Robert Slenes, de Sidney Mintz, de Richard Price, e de vários outros autores que analisaram dessa perspectiva as sociedades caribenhas e do sul dos Estados Unidos ${ }^{4}$. Para isso foi preciso me iniciar no estudo de culturas africanas, especialmente centro-africanas (pois foram estas que deram aos reinados negros a contribuição cultural mais significativa), e no estudo do catolicismo na África, uma vez que ele já marcava presença no reino do Congo antes mesmo de chegar ao que foi chamado de Brasil pelos portugueses. John Thornton foi um autor fundamental para começar a entender o que ele chamou de "catolicismo africano", forjado no reino

USP, 1993; Anderson José Machado de Oliveira, "Devoção e Caridade. Irmandades religiosas no Rio de Janeiro imperial (1840-1889)", Dissertação de mestrado, Departamento de História, UFF, Niterói, 1995; Marcelo MacCord, "O Rosário do Homens Pretos de Santo Antonio: alianças e conflitos na história social do Recife, 1848-1873", Dissertação de Mestrado, Departamento de História, UNICAMP, Campinas, 2001; Elizabeth Kiddy, "Brotherhoods of Our Lady of the Rosary of the Blacks: Community and Devotion in Minas Gerais, Brazil.”, UMI Dissertation Information Service, Albuquerque, The University of New Mexico, 1998.

${ }^{3}$ Marina de Mello e Souza, Reis negros no Brasil escravista. História da festa de coroação de rei congo, Belo Horizonte, Editora UFMG, 2002.

${ }^{4}$ Sidney Mintz e Richard Price, The Birth of African-American Culture. An Anthropological Perspective, Boston, Beacon Press, 1992 (first edited 1976); Richard Price, Alabi's World, Baltimore, The Johns Hopkins University Press, 1990; Robert Slenes, "Malungu ngoma vem!' África coberta e descoberta no Brasil”, Revista USP, n.12, p.48-67, dez/jan/fev 19911992 e Na senzala uma flor: as esperanças e as recordações na formação da família escrava - Brasil sudeste, século XIX, Rio de Janeiro, Nova Fronteira, 1999. 
do Congo e espalhado para regiões vizinhas. ${ }^{5}$ Além de considerar na minha análise dos reinados negros brasileiros algumas de suas possíveis relações com o chamado "catolicismo africano", o conhecimento das formas de organização social e política das sociedades africanas, e de seus sistemas culturais, permitiu que eu construísse uma interpretação da força da presença dos reis negros, e posteriormente das congadas, entre muitas comunidades brasileiras. É essa minha interpretação que pretendo expor aqui, no final dialogando com trabalhos posteriores ao meu, que também abordaram os reinados negros no Brasil, como os de Linda Heywood e Elizabeth Kiddy. ${ }^{6}$

No Brasil existiram reis negros entre algumas comunidades afrodescendentes, fossem elas quilombolas ou grupos de trabalho, mas principalmente nas que se agrupavam em torno de irmandades leigas de devoção a determinados santos, com destaque para Nossa Senhora do Rosário e São Benedito. A principal atividade dessas irmandades, além daquelas relacionadas ao enterro dos irmãos, era a realização da festa anual em homenagem ao seu orago, ou seja, santo de devoção, e nela o rei desfilava em cortejo pela cidade, seguido de sua corte, de seus músicos, de seus dançadores, que podiam apresentar encenações, algumas vezes descritas por observadores atentos a essas manifestações da cultura afro-brasileira, o que permitiu que informações sobre elas chegassem até nós. Enquanto a maioria dessas descrições são do século XIX, para o século XVIII podemos recorrer a um ou outro registro feito por observadores dos reinados negros e a documentos de irmandades de "homens pretos" (este é o termo mais comum pelo qual elas são identificadas nos documen-

\footnotetext{
${ }^{5}$ Entre as obras de John Thornton, ver especialmente África and Africans in the Making of the Atlantic World, 1400-1680, Cambridge, Cambridge University Press, 1992; "On the trail of voodoo: African Christianity in Africa and the Americas", The Americas, 55, p. 261- 278, jan. 1988; "Early Kongo-Portuguese relations: a new interpretation", in: History in Africa. A Journal of Method, Massachusetts, Brandeis University, African Studies Association, v.8, p. 183-204, 1981; "The Development of an African Catholic Church in the Kingdom of Kongo, 1491-1750”, Journal of African History, 25, p. 147-167, 1984.

${ }^{6}$ Linda M. Heywood, “As conexões culturais angolano-luso-brasileiras”, em Entre Áfricas e Brasis, organizado por Selma Pantoja, São Paulo, Marco Zero / Paralelo 15, 2001 (tradução brasileira de "The Angolan-Afro-Brazilian Cultural Connections", Slavery and Abolition, vol.20,n.1, Spring 1999, pp.9-23); Elizabeth W. Kiddy, "Who is the King of Congo? A New Look at African and Afro-Brazilian Kings in Brazil”, in Central Africans and Cultural Transformations in the American Diaspora, edited by Linda M. Heywood, Cambridge, Cambridge University Press, 2002.
} 
tos), onde estão descritas as normas de escolha, as condições impostas aos candidatos aos cargos e suas obrigações.

Conforme minha interpretação, esses reis negros no Brasil escravista eram pólos aglutinadores de comunidades que construíam novas identidades a partir dos seus legados africanos, acomodados à estrutura da sociedade escravista brasileira. $\mathrm{O}$ intuito da minha análise foi mostrar um processo por meio do qual alguns africanos e afrodescendentes elaboraram uma identidade negra católica. Na constituição dessa identidade, foram importantes as irmandades de "homens pretos", no interior das quais existiu a maioria dos reinados negros; contaram as normas de convivência entre escravos e senhores, mas também estiveram presentes as experiências do "catolicismo africano", conhecido de muitos centro-africanos escravizados que foram levados para o Brasil.

Os indícios para o século XVIII mostram que havia celebrações em torno de reis de diversas nações, preferencialmente centro-africanas mas não só ${ }^{7}$, enquanto as fontes relativas ao século XIX falam quase só em rei do Congo. Para mim, a proliferação no século XIX do título de rei do Congo, havendo antes uma variedade de "nações" que escolhiam e festejavam seus reis, deveu-se ao fato da referência a este reino ter significados importantes tanto para senhores e administradores coloniais como para centro-africanos escravizados, que tinham de refazer suas vidas na sociedade escravista brasileira, e que eram maioria nas áreas de maior incidência dos reinados negros. Para eles a experiência do catolicismo também era um elo com a África natal (crescentemente idealizada à medida que se afastava no tempo), devido à existência de chefes que se diziam católicos no Congo e em Angola e à incorporação de ritos e objetos de culto do catolicismo por algumas populações centro-africanas. Essa familiaridade anterior com formas de catolicismo africano ajudou a construção de uma identidade elaborada e reproduzida por meio dos reinados negros realizados nas irmandades. Mas além desse aspecto de ordem mais

\footnotetext{
7 “Apenas amanhecia o dia de Reis, o campo de São Domingos, nas proximidades da capela, opulentava-se de um espetáculo variado e estranho em que Moçambiques, Cabundás, Benguelas, Rebolos, Congos, Cassanges, Minas, e a pluralidade finalmente dos representantes das nações d'África, escravos no Brasil, exibiam-se autênticos, cada qual com seu característico fundamental, seu tipo próprio, sua estética privativa." Mello Moraes Filho, Festas e tradições populares do Brasil, $3^{\mathrm{a}}$ edição, Rio de Janeiro, F.Briguiet \& Cia. Editores, 1946, p. 383. (A descrição se refere a festa do século XVIII.)
} 
simbólica, as próprias formas de organização política africanas, nas quais era central a figura do chefe, encontraram receptividade junto a tradições da religiosidade popular européia, e particularmente lusitana, segundo as quais eram eleitos alguns reis de festa, como no caso da festa do Divino Espírito Santo.

Já para os senhores e administradores da sociedade colonial, as festas em torno de um rei do Congo eram na maior parte das vezes aceitas por serem feitas a partir das irmandades leigas de devoção a santos católicos, instituições que integravam os africanos e seus descendentes às normas da sociedade escravista. Mas além desse aspecto considerado como disciplinador de comunidades negras, sempre potencialmente ameaçadoras, havia elementos simbólicos igualmente importantes para a aceitação de reis do Congo, ou pelo menos tolerância à sua existência. Estes se relacionavam à história do império português, que legitimou sua expansão em parte na ação missionária, justificando-a pela necessidade de converter ao catolicismo o gentio dos territórios reivindicados. No que diz respeito à África, primeiro espaço explorado pelos portugueses, os sacerdotes tiveram grande dificuldade em difundir a religião católica, com a exceção do reino do Congo, cujos principais chefes aceitaram o batismo em 1491 e a partir de então adotaram o catolicismo como a religião que fundamentava o poder central, mesmo sem abandonar as crenças ancestrais e as formas tradicionais de legitimação do poder. A crônica portuguesa da época registrou com detalhes os episódios ligados à conversão dos chefes congoleses e no século XVI houve uma grande aproximação entre Portugal e o Congo, que no entanto manteve sua soberania. ${ }^{8} \mathrm{O}$ momento de maior força do chamado reino do Congo - um determinado território cujas aldeias se sujeitavam a uma autoridade central - foi o período do governo de Mbemba Nzinga (1507-1542), batizado ainda criança com o nome de Afonso no momento inaugural da aceitação do catolicismo por parte de alguns chefes congoleses. D. Afonso I entrou para a história como o mais importante rei católico do Congo, mantendo correspondência com D. João II, D. Manuel I e D. João III de Portugal e apoiando a disseminação do catolicismo entre a população por ele governada. Essa vitória da ação missionária liderada pela Coroa portuguesa foi reme-

\footnotetext{
${ }^{8}$ Para a conversão dos chefes congoleses, ver entre outras, a narrativa de Rui de Pina, "Relação do Reino do Congo", em Carmem M. Radulet, O cronista Rui de Pina e a "Relação do Reino do Congo", Lisboa, Imprensa Nacional, Casa da Moeda, 1992.
} 
morada por séculos, dramatizada em festas públicas e fartamente utilizada para o enaltecimento do império português. ${ }^{9}$

Assim, considerando os reinados negros como manifestações culturais com significados distintos para aqueles que os realizavam, ou seja as comunidades negras, e para aqueles que tinham o controle da sociedade escravista, para uns eles seriam formas de organização social e de construção de novas identidades, e para outros seriam comprovação do domínio sobre a comunidade negra e de um poder articulado ao império. Dessa forma, a unificação dos diversos reis de nação em uma única designação, de rei do Congo, liga-se, no meu entender, a esses dois universos culturais, o dos negros e o dos brancos. De um lado houve a consolidação de uma identidade mais uniforme adotada por africanos de origens diferentes, que passaram a se ver como membros de uma comunidade católica negra, parte da sociedade brasileira para a qual eles ou seus antepassados foram trazidos. De outro lado, o lugar de destaque que o reino do Congo ocupava no imaginário lusitano, principal matriz das maneiras de pensar da classe senhorial brasileira e que permaneceu presente mesmo quando o Brasil se tornou independente de Portugal, ajudou a aceitação das congadas e por meio delas a integração de alguns dos grupos de descendentes de africanos à sociedade brasileira.

A essa interpretação de caráter mais simbólico, podemos somar as informações relativas ao tráfico de escravos centro-africanos para o sudeste brasileiro, pois no século XIX, quando se consolidou a designação de rei do Congo nos reinados negros existentes no Brasil, cresceu a quantidade de africanos embarcados nos portos da região do antigo reino do Congo. A vigilância do fisco português sobre as transações comerciais que aconteciam no porto de Luanda e o cerco dos britânicos sobre os navios negreiros fez com que os traficantes reativassem os portos mais próximos à foz do rio Congo, o que também acarretou uma mudança nas rotas interiores de abastecimento de escravos, que passaram a ser pessoas mais ligadas à área de influência do mani Congo. No território que até o século XVII havia existido uma unidade política coesa, no século XIX conjuntos de aldeias tinham autonomia administra-

\footnotetext{
${ }^{9}$ A esse respeito ver também Silvia Lara, "Significados cruzados: as embaixadas de congos na Bahia setecentista", em Carnavais e outras f(r)estas, organizado por Maria Clementina Pereira Cunha, Campinas, Cecult / Editora Unicamp, 2001.
} 
tiva e econômica, mas mantinham uma unidade simbólica, pois os chefes locais ainda reconheciam a autoridade do mani Congo: o chefe principal, que continuava recorrendo ao catolicismo para reforçar e legitimar sua autoridade sobre os demais. ${ }^{10}$ Assim, com a chegada de africanos traficados pelas rotas do Congo no século XIX, os laços das comunidades negras brasileiras com aquela região se estreitaram novamente depois de um longo predomínio do porto de Luanda e da região de Angola. ${ }^{11}$

Ao estudar os reis negros no Brasil escravista eu queria encontrar uma explicação para a disseminação dos festejos em torno de um rei do Congo por grande parte do território brasileiro no século XIX. A partir da reconstituição que me foi possível fazer da história da festa de coroação de reis do Congo no Brasil, propus, na ocasião, o uso do termo "rei congo" como indicador de uma determinada identidade, expressa num mito vivido nas teatralizações que ocorriam em alguns festejos, como contam relatos do século XIX. Por estarem expressos nesse mito sentimentos que ultrapassam em muito o reino do Congo tal como existiu historicamente, optei por usar o termo como uma categoria e escrevê-lo com letra minúscula. Para mim, o termo "rei congo" remete a uma idéia de África construída no Novo Mundo e ao ser usado como uma categoria abstrata do conhecimento, e não como a descrição de uma realidade histórica, se torna mais geral, como a identidade para cuja construção ele serviu.

A sociedade escravista no interior da qual algumas comunidades negras construíram essa identidade católica negra, para a qual o rei era um catalizador, era um arcabouço de coerção e de controle sobre os afrodescendentes. E o surpreendente, para retomar uma idéia com a qual comecei esse texto, é que escravos, negros livres e libertos ocupassem as ruas das cidades e os terreiros das fazendas com procissões, cantos, danças e encenações toleradas e às vezes até apreciadas pelos senhores, pelos brancos, pelos pardos embranquecidos pela ascensão social. Com a garantia da liberdade oferecida pelo momento da

\footnotetext{
${ }^{10}$ A esse respeito ver Susan Herlin Broadhead, "Beyond decline: the Kingdom of the Kongo in the eighteenth and nineteenth centuries." International Journal of African Historical Studies, 12, pp. 615-650, 1979.

${ }^{11}$ Ver, entre outros trabalhos, Susan J. Herlin, "Brazil and the Commercialization of Kongo, 1840-1870", em Enslaving Connections. Changing Cultures of Africa and Brazil During the Era of Slavery, edited by José C. Curto and Paul E. Lovejoy, New York, Humanity Books, 2004.
} 
festa, chefes negros se mostravam à frente dos grupos que os escolheram, que acatavam a sua autoridade, que contavam com sua proteção e com que eles assumissem todos os encargos associados àquele lugar de liderança. ${ }^{12}$ Mas também eram freqüentes os pedidos para que os reinados negros fossem proibidos, porque vistos como ameaçadores à ordem. A liberalidade que podia cercálos, com a tolerância a uma inversão de lugares característica do tempo da festa, quando a ruptura do cotidiano permite que o mundo, mesmo numa sociedade escravista, fosse posto de cabeça para baixo, tinha como contrapartida a solicitação de medidas repressoras. É o que vemos numa petição escrita em 1771 por um vigário mineiro que não se conformava com o fato dos reis negros se atribuírem autoridade (reconhecida por muitos) durante a vigência de seus reinados festivos, exigindo que as pessoas se descobrissem à sua passagem, que lhes cedessem os melhores lugares na igreja ou que obedecessem a ordens suas de natureza diversa, como por exemplo soltar escravos dos castigos ou mesmo da cadeia. ${ }^{13}$ Em um outro extremo das maneiras como a sociedade escravista lidava com os reinados negros, havia senhores que emprestavam jóias a seus escravos, permitiam que se ausentassem, e às vezes participavam ativamente da farsa teatral, quando reconheciam a autoridade, para eles burlesca, do rei. ${ }^{14}$

\footnotetext{
12 “Após irem à missa cerca de 400 homens e mulheres elegeram um rei e uma rainha, e marcharam pelas ruas cantando, dançando e recitando os versos que fizeram, acompanhados de oboés, trombetas e tambores bascos. Estavam vestidos com as roupas de seus senhores e senhoras, com correntes de ouro e brincos de ouro e pérolas, alguns deles mascarados. Todas as diversões desta cerimônia lhes custaram 100 escudos. O rei e seus oficiais não fizeram nada em toda essa semana, além de andarem solenemente, com a espada e a adaga ao seu lado." (Observação feita em 1666). Urbain Souchu Rennefort, Histoire des Indes Orientales. Paris: Arnoul Seneuze, 1688. Citado em Paulo Augusto Castagna, "Fontes bibliográficas para a pesquisa da prática musical no Brasil nos séculos XVI e XVII, v. III (documentação), p.485. Dissertação de Mestrado, Escola de Comunicações e Artes, Universidade de São Paulo, São Paulo, 1991.

${ }^{13}$ Petição do Padre Leonardo de Azevedo Castro, vigário colado de São Sebastião de Mariana, Minas Gerais, transcrita em parte por Carlos Drummond de Andrade, "Rosário dos homens pretos", em Poesia completa e prosa, Rio de Janeiro, Companhia José Aguilar Editora, 1973, pp. 810 a 815.

${ }^{14}$ Como contam Spix e Martius, que assistiram a um desses reinados em 1818 em Diamantina: "Chegando à igreja da Mãe de Deus, preta e só dos negros, o rei deposto entregou o cetro e a coroa ao seu sucessor, e este fez então uma visita de gala, na sua nova dignidade, ao intendente do Distrito Diamantino, com toda sua corte. O intendente, já prevenido dessa visita, esperou o seu hóspede real em camisola de dormir e carapuça. O recém-eleito, negro forro e sapateiro de ofício, ao avistar o intendente, ficou tão atrapalhado, que, ao ser convidado para sentarse no sofá, deixou cair o cetro. O delicado Ferreira da Câmara, apanhou-o, e, rindo, o resti-
} 
Mas não era só farsa que havia no teatro (ou nas danças dramáticas, como tão bem definiu Mário de Andrade) ${ }^{15}$, pois para mim é justamente nele que reside o núcleo da construção mítica de uma identidade negra católica no Brasil escravista. Coroados na igreja pelo padre no dia da festa do orago da irmandade que os abrigava, os reis desfilavam com seus séquitos pelos bairros em que moravam mas também pelos espaços mais nobres das cidades, praças e ruas onde se situavam os prédios da administração e das moradias das pessoas importantes. O grupo ostentava com orgulho suas roupas especiais, o mais luxuosas possíveis, meia, calção, sapatos de fivela, camisas com babados e casacas engalonadas, manto, cetro e coroa, para as rainhas vestidos à moda européia. As cortes festivas usavam roupas semelhantes às daquelas com que foram descritos e retratados os chefes africanos recebendo emissários europeus, geralmente obtidas nas negociações com os comerciantes atlânticos, que tinham que oferecer aos chefes as mercadorias que mais lhes agradavam para obter as licenças para a compra de escravos. O que para os senhores luso-brasileiros indicava a adoção dos padrões europeus e a subordinação, para a comunidade negra devia ser lembrança de grandes chefes que por terem boas relações com os comerciantes europeus que atuavam em suas terras tinham acesso àquelas roupas, que os distinguiam dos menos poderosos do que eles. ${ }^{16}$

tuiu ao rei já cansado, com as palavras: - 'Vossa Majestade deixou cair o cetro!' O coro musical exprimiu com barulhenta toada a respeitosa gratidão pelo gesto do intendente, e, finalmente, saiu toda a multidão, depois de haver, segundo o costume dos escravos, dobrado o joelho direito deante das pessoas da casa, e, caminhando alegremente pelas ruas, o rei e a rainha voltaram às suas choças." J.B. Von Spix e C.F.P. Von Martius, Viagem pelo Brasil, Rio de Janeiro, Imprensa Nacional, 1938, v.II, p.129.

${ }^{15}$ Mário de Andrade, "Os congos", em Danças dramáticas do Brasil, tomo 2, Belo Horizonte, Editora Itatiaia, Brasília, Instituto Nacional do Livro, 1982.

16 "Ficamos parados à porta quando apareceu um volumoso número de negros e negras, vestidos de algodão branco e de cor, com bandeiras ao vento e tambores soando. Quando se aproximaram, descobrimos, no meio, o Rei, a rainha e o Secretário de Estado. Cada um dos primeiros trazia na cabeça uma coroa de papel colorido e dourado. O Rei estava vestido com uma velha roupa de cores diversas, vermelho, verde e amarelo, manto, jaleco e calções. Trazia na mão um cetro de madeira, lindamente dourado. A Rainha envergara um vestido de seda azul, da moda antiga. O humilde Secretário ostentava tantas cores quanto seu chefe, mas era evidente que sua roupa provinha de várias partes, umas muito estreitas e outras demasiado amplas para ele. As despesas com a sagrada cerimônia deviam ser pagas pelos negros e por isso, no meio da igreja, estava uma mesinha, com o tesoureiro dessa Irmandade preta e outros dignitários, e sobre ela uma pequena caixa para receber o dinheiro.” (Observação feita em 1814.) Henry Koster, Viagens ao nordeste do Brasil, tradução e notas de Luis da Câmara Cascudo, São Paulo: Companhia Editora Nacional, 1942, p. 354. 
Acompanhando os reis e suas cortes vinham tocadores de instrumentos de origem tanto européia quanto africana: diferentes tipos de tambores, pianos de dedo, marimbas, instrumentos de corda, além dos que dançavam com passos e gestos tipicamente africanos, descritos com espanto e repugnância pela maioria dos registros. ${ }^{17}$ Muitas vezes, junto aos personagens reais com trajes de estilo europeu, vinham outros, vestidos de maneiras africanas, envoltos em peles, carregados de colares, pulseiras, guizos, e penas na cabeça à semelhança dos sacerdotes centro-africanos. As músicas tinham ritmos africanos e as letras misturavam palavras africanas com um português com gramática e sintaxe alterados. Se considerarmos que as letras cantadas então eram semelhantes às que foram coletadas a partir do final do século XIX e início do XX, elas falavam de situações que remetiam a temas familiares às comunidades negras, como o aprisionamento na África, a travessia do oceano, a adoção do catolicismo, a interferência dos santos na vida cotidiana, situações ligadas ao cativeiro e à inserção dos africanos e seus descendentes na sociedade escravista brasileira. $\mathrm{O}$ áuge dos cortejos festivos era a dança dramática, nem sempre presente, mas descrita por vários observadores. ${ }^{18}$

17 "O novo rei dos negros recebeu oficialmente a visita de um enviado estrangeiro à corte do Congo (a denominada congada). A família real e a corte, em roupas de gala, dirigiram-se com pompa à praça do Mercado; o rei e a rainha sentaram-se em cadeiras, à sua direita e esquerda, acomodaram-se, em bancos baixos, os ministros, camareiros e camareiras e os mais dignitários do reino. Deante deles, estavam colocados, em dupla fila, os músicos da banda, com sapatos amarelos e vermelhos, meias pretas e brancas, calças vermelhas e amarelas, com capinhas de seda, todas rotas, e faziam uma algazarra infernal com tambores, flautas, pandeiros, chocalhos e com a chorosa marimba; os dançadores anunciaram o enviado com pulos e cabriolas, com as mais singulares caretas e as mais profundas mesuras, e traziam os seus presentes, apresentando tão bizarro espetáculo, que se imaginava estar deante de um bando de macacos. Suas majestades pretas a princípio repeliram a visita do estrangeiro, mas acabaram recebendo-o com estas palavras: 'Que lhes estavam abertas as portas e o coração do rei'.” J.B. Von Spix e C.F.P. Von Martius, Viagem pelo Brasil, Rio de Janeiro, Imprensa Nacional, 1938, v.II, p.130.

${ }^{18}$ "Fazem todos os anos este extravagante carnaval, adquirindo o eleito grande influência sobre os companheiros. A cena era muito curiosa, misturando singularmente as reminiscências da costa africana com os costumes brasileiros e cerimônias religiosas. A princípio, o rei do Congo, em companhia de sua metade, vem ocupar uma das cadeiras postas de antemão para uso da corte. Ambos estão magnificamente vestidos, trazem coroas de prata maciça e cetros dourados. Um grande guarda-chuva os garante da influência da lua, que vem nascendo. Coisa digna de reparo, o rei traz uma máscara preta, como se tivesse receio de que a permanência no país lhe tivesse desbotado a cor natural. A corte, em cujo traje se misturam todas as cores e os enfeites mais extravagantes, senta-se de cada lado do casal de reis; 
Em essência essa dança representava o enfrentamento entre o exército de um reino pagão e o do rei cristão do Congo, que se apresentava cercado de seus familiares, chefes militares e religiosos. Embaixadores traziam mensagens do reino distante, geralmente desafiadoras, travando-se então uma batalha dançada e cantada, sempre vencida pelo exército cristão do Congo. Algumas vezes as embaixadas eram amistosas e os emissários do rei pagão ausente vinham apresentar sua adesão aos festejos católicos. As dramatizações foram descritas com mais ou menos detalhes e o conteúdo do que era falado só passou a ser registrado com mais freqüência a partir do século XX. Mas se pensarmos que as narrativas orais remetem a tradições que vêm de longa data, podemos acreditar que as falas das dramatizações descritas pelos observadores do XIX não eram essencialmente diferentes das observadas algumas décadas depois.

Conforme a minha interpretação, nessas danças dramáticas estavam simbolizados elementos centrais na formação da identidade negra católica das comunidades que se uniam em torno de reis, que serviam de catalisadores das diferentes identidades africanas anteriores, diluídas com a passagem do tempo, transformando-se numa identidade africana una, ligada ao campo do mítico e do imaginado. $\mathrm{O}$ rei congo católico, além de sinalizar para uma integração à sociedade escravista na qual o catolicismo tinha um papel de destaque, lembrava tempos de glória em terra natal, associada ao poderoso reino do Congo, aliado de povos europeus e cujos chefes tiveram poder invejável. A rememoração simbólica do reino africano católico afirmava uma "africanidade", ou seja uma conexão com a África construída a partir do Brasil e da experiência aqui vivida, que indicava uma particularidade da comunidade negra, uma identidade própria que a distinguia mesmo quando adotava o catolicismo e outras tradições de origem portuguesa como a organização em irmandades leigas. A vitória dramatizada dos homens do rei

vem depois uma infinidade de outros personagens, os mais consideráveis dos quais eram sem dúvida grandes capitães, guerreiros famosos ou embaixadores de potências longínquas, todos paramentados à moda dos selvagens do Brasil, com grandes topetes de penas, sabres de cavalaria ao lado, e o escudo no braço. Nessa balbúrdia, confundiam-se danças nacionais, diálogos entre pessoas, entre estas e o rei ou entre o rei e a rainha, combates simulados e toda espécie de cambalhotas dignas dos macacos mais exercitados. A coisa mais divertida era porém um preto mascarado de branco, e vestido com a farda vermelha do soldado inglês; trazia um violão e era acompanhado por uma orquestra, por assim dizer nacional. A escuridão acabou por engolir estes personagens, que não podiam querer mais do que nela se confundir." (Observação feita em 1843.) Francis Castelnau, Expedição às regiões centrais da América do Sul, tradução Olivério M. de Oliveira Pinto, São Paulo, Companhia Editora Nacional, 1949, p.171. 
congo sobre os pagãos, que acabavam por se converter, confirmava a aceitação de uma identidade nova, adequada ao mundo para o qual foram trazidos como escravos, mas onde também aprenderam formas de conquistar a liberdade ou condições menos árduas de cativeiro. Festejar o rei congo depois deste ter sido coroado na igreja pelo sacerdote católico, o que remetia a ser ele, tal como em terras africanas, um intermediário privilegiado entre este mundo e o outro, entre o cotidiano e o além, entre os homens e os espíritos e antepassados, também era festejar uma maneira específica de ser. Nessa maneira de ser os laços com a África eram fundamentais, mas também os laços com o catolicismo.

A dança dramática que era feita no século XIX, quando foi chamada de congada, talvez só então tenha se constituído da forma como foi descrita, pois os relatos mais antigos, do XVII e do XVIII, falam apenas em cortejos com danças e música, sem mencionar teatralizações, como as que já havia há muito em festas lusitanas, representando por exemplo o embate entre mouros e cristãos. Mas provavelmente foram tradições africanas que estiveram na base da formação das congadas, apesar da semelhança que também tinham com tradições lusitanas, como mostram as descrições de batalhas rituais travadas na região do reino do Congo no século XVII por ocasião da entronização e de cerimônias fúnebres de chefes, ou de festas em sua homenagem. ${ }^{19}$ A descrição feita por Gaspar Barléus em meados do século XVII das danças realizadas por embaixadores congoleses enviados a Maurício de Nassau, no Recife, também aponta para as matrizes africanas das congadas. ${ }^{20} \mathrm{O}$ mais provável é que

\footnotetext{
${ }^{19}$ Por ocasião das cerimônias fúnebres (tambo) em honra da rainha Njinga (cujo nome cristão era Ana de Souza), em 1663 no reino de Matamba, na África central, cerca de 8000 soldados, por cinco dias, participaram de danças rituais que simulavam batalhas conforme a descrição do padre Cavazzi, que assistiu pessoalmente aos ritos: "No mesmo instante foi dado o alarme e todos os soldados, com o porte mais feroz que se possa imaginar, começaram a representar as façanhas de dona Ana, imitando-a no assalto, na retirada, na preparação das ciladas, na defesa, na perseguição dos inimigos. Um esquadrão defrontava outro, num arremedo de peleja em que uns fingiam ceder o lugar, outros defendê-lo e outros reconquistá-lo. Alguns caíam como mortos, outros rendiam-se prisioneiros. Um grupo fugia, depois recompunha-se; outro vencia, outro descansava um bocado. Era tão encarniçada aquela fingida batalha, que qualquer pessoa a teria julgado verdadeira.” João António Cavazzi de Montecúccolo, Descrição histórica dos três reinos do Congo, Matamba e Angola, tradução, notas e índice do Padre Graciano Maria Leguzzano, Lisboa, Junta de Investigação do Ultramar, 1965, vol II, livro sexto, p. 156.

20 "Eles eram de compleição robusta e sadia, rosto negro, muito ágeis de membros, que ungiam para maior facilidade de movimento. Vimo-lhes as danças originais, os saltos, os
} 
as tradições centro-africanas de celebrar momentos chaves ligados às chefias com danças e batalhas rituais tenham sido recriadas em algumas comunidades negras que no Brasil se organizaram em torno dos reinados negros, sendo associadas pelos senhores de origem portuguesa a tradições medievais, ligadas a embaixadas, entradas reais e à encenação de lutas entre mouros e cristãos, as chamadas mouriscadas. ${ }^{21}$

A minha interpretação de como os reinados negros foram criados a partir de contribuições centro-africanas é próxima da abordagem de autoras como Linda Heywood e principalmente Elizabeth Kiddy, que se alinham a uma perspectiva segundo a qual os centro-africanos escravizados recriaram suas culturas nas novas condições da sociedade escravista brasileira a partir de suas culturas de origem. A minha maior crítica a essas autoras e à escola a que elas se alinham é que suas análises pouco percebem a incorporação, por parte das comunidades negras, dos elementos lusitanos ou luso-brasileiros, assim como não dão o devido destaque à relação de dominação que os senhores e administradores tinham com os escravos, forros e mesmo negros livres. O peso da dominação e os processos de mestiçagem são minimizados principalmente por Linda Heywood, que destaca a recriação de culturas africanas no Brasil escravista. Essa é uma perspectiva que está sendo disseminada por estudos recentes entre os quais se alinha também James Sweet, que ao chamar seu livro por Recreating África deixa claro que entende as manifestações afro-brasileiras como recriações africanas adequadas à nova situação de vida encontrada na América pelos africanos e seus descendentes. ${ }^{22}$ Essa perspectiva é acentuada

temíveis floreios de espadas, o cintilar dos olhos simulando ira contra o inimigo. Vimos também a cena em que representavam o seu rei sentado no solo e testemunhando a majestade por um silêncio pertinaz. Depois vimos a cena dos embaixadores vindos do estrangeiro e adorando ao rei, conforme o cerimonial usado entre suas nações, as suas posturas, a imitação das suas cortesias e mostras de acatamento, cousas que, para divertimento dos nossos, exibiam, um tanto alegres depois de beberem." Gaspar Barléus, História dos feitos recentemente praticados durante oito anos no Brasil e noutras partes sob o governo do ilustríssimo João Maurício, conde de Nassau (1647), tradução e anotações de Cláudio Brandão. Rio de Janeiro: Serviço Gráfico do Ministério da Educação, 1940, p. 254.

${ }^{21}$ As celebrações portuguesas ligadas ao poder real, são estudadas, entre outros, por Ana Maria Alves, em As entradas régias portuguesas. Uma visão de conjunto, Lisboa, Livros Horizonte Ltda, s/d. e Rita Gomes Costa, em A corte dos reis de Portugal no final da Idade Média, Lisboa, Difel, 1995.

${ }^{22}$ James H. Sweet, Recreating África. Culture, Kinship, and Religion in the AfricanPortuguese World, 1441-1770. Chapel Hill, The University of North Carolina Press, 2003. 
pela pouca densidade da compreensão que esses autores têm da sociedade colonial brasileira na qual ocorriam as situações que analisaram em seus textos. Entretanto, ao espalhar o olhar para Portugal, Angola e Brasil esses autores chamam a atenção para as ligações entre essas partes do império português, que tinha no Atlântico um espaço privilegiado de existência. As conexões que eles identificam entre práticas e crenças centro-africanas e brasileiras são extremamente interessantes, mas as sutilezas dos processos de construção da sociedade brasileira (nos quais sem dúvida os africanos e afrodescendentes foram fundamentais), e o peso das normas ditadas a partir da metrópole colonial, são pouco percebidos. Talvez a característica mais marcante da sociedade brasileira desde os seus primórdios seja a mestiçagem. Para lidar com ela a administração colonial teve que alterar as regras de uma sociedade estamental de antigo regime, abrindo exceções quanto às exigências de pureza de sangue para ocupar cargos na administração laica e religiosa, curvando-se à ascensão de mestiços a lugares até então reservados aos brancos católicos. ${ }^{23} \mathrm{~A}$ força das misturas ocorridas no Brasil é aspecto que escapa a esses estudiosos norte-americanos, que preferem pensar em termos de áreas de preservação de aspectos de culturas africanas, mesmo que modificadas pelas determinações da nova realidade.

No seu artigo "As conexões culturais angolano-luso-brasileiras" (em inglês "The Angolan-Afro-Brazilian Cultural Connections"), Linda Heywood aborda manifestações católicas negras formadas a partir da diáspora imposta pelo tráfico de escravos a milhões de centro-africanos. As irmandades católicas de homens negros em Lisboa, Luanda e em menor grau no Brasil, e a coroação de reis do Congo em Portugal e em menor grau no Brasil são temas que ela rastreia tendo por base alguns poucos autores. $\mathrm{O}$ seu desconhecimento acerca do Brasil e da bibliografia brasileira sobre catolicismo negro faz com que chegue a conclusões tão controversas como dizer que a "cultura crioula" brasileira é herança portuguesa, assim como dizer que foi de Luanda que veio o costume dos negros se organizarem em irmandades de louvor a Nossa Senho-

\footnotetext{
${ }^{23}$ Silvia H. Lara, em Fragmentos Setecentistas: escravidão, cultura e poder na América portuguesa, Tese de Livre-Docência, Departamento de História, IFCH, Unicamp, Campinas, 2004, estuda o lugar dos mestiços no império português, abrindo o campo de investigação ainda quase inexplorado da questão da mestiçagem no Brasil colonial.
} 
ra do Rosário e de outros santos de sua predileção. ${ }^{24}$ Acredita ainda que padres convertidos no Congo ajudaram a disseminar no Brasil uma religiosidade afro-católica, quando o que as fontes apontam é justamente o contrário, ou seja, como sacerdotes católicos brasileiros atuaram como missionários em Angola. ${ }^{25}$ Para ela os festejos de reis do Congo no Brasil eram lembranças de coisas ocorridas no Congo e se ligavam não só ao "catolicismo africano" como às relações entre as Dioceses de Angola e do Brasil. Tendo o mérito de propor uma análise de viés atlântico, o conhecimento precário de Linda Heywood sobre a sociedade e a historiografia brasileiras impede que ela alcance sua meta, chegando a conclusões problemáticas.

Já Elizabeth Kiddy tem maior familiaridade com o Brasil pois fez pesquisa minuciosa em arquivos brasileiros além de assistir e participar ativamente de congadas que são feitas ainda hoje nas cercanias de Belo Horizonte. ${ }^{26}$ Mas o seu trabalho que interessa aqui é resultado de pesquisa bibliográfica e foi exposto em 1999 num congresso na Howard University organizado por Linda Heywood e publicado em 2002. Ali Kiddy se perguntou quem era o rei do Congo no Brasil dos séculos XVIII e XIX. Fazendo um caminho bastante próximo do que eu mesma fiz em tese defendida em 1999 e publicada em 2002, ela se opõe às interpretações mais antigas para as quais os festejos em torno de um rei do Congo remetem ao triunfo da cultura européia sobre a africana e defende que eles "simbolizam um processo de tradução cultural e transformação que representa a continuação da cultura centro-africana entre os afro-brasileiros" ${ }^{27}$ A ambigüidade presente nessa afirmação, que fala em transformação e também em continuidade, no meu entender está presente em todo o texto, no qual a autora se refere sempre à recriação e reconstrução de estruturas

\footnotetext{
24 "As observações de Bastide sobre a popularidade desses santos e de Nossa Senhora do Rosário entre a população africana e crioula [...] certamente são remanescentes de coisas que ocorreram durante o processo no Congo.” Linda M. Heywood, "As conexões culturais angolano-luso-brasileiras”, em Entre Áfricas e Brasis, p. 65.

${ }^{25}$ Como mostra a pesquisa de Lucilene Reginaldo, apresentada em sua tese de doutorado recentemente defendidada: "Os Rosários dos Angolas: Irmandades negras, experiências escravas e identidades africanas na Bahia setecentista", Unicamp, 2005.

${ }^{26}$ Elizabeth Kiddy, "Brotherhoods of Our Lady of the Rosary of the Blacks: Community and Devotion in Minas Gerais, Brazil.", UMI Dissertation Information Service, Albuquerque, The University of New Mexico, 1998.

${ }^{27}$ Elizabeth Kiddy, "Who is the King of Congo? A New Look at African and Afro-Brazilian Kings in Brazil", in Central Africans and Cultural Transformations in the American Diaspora, edited by Linda M. Heywood, Cambridge, Cambridge University Press, 2002, pp. 155-182.
} 
sociais e manifestações culturais centro-africanas, não atentando para o que é incorporado da sociedade branca senhorial, como a própria adoção das irmandades como formas de organização social. Também aqui o que impede a autora de fazer uma análise mais complexa dos processos em curso é a abordagem superficial do contexto no qual as manifestações ocorrem, pouco considerando as determinações de uma relação entre senhores e escravos. Mas a semelhança entre o trabalho de Kiddy e partes do meu próprio trabalho, seja na escolha de seus temas, de suas fontes, ou em algumas das conclusões propostas, não leva a autora a se identificar comigo, como ela mesma indica no final do seu artigo, quando diz ter chegado a conclusões diferentes das minhas. Creio que a referida diferença se encontra no fato de eu chamar atenção para a especificidade do processo de formação de identidades nos quais se destacavam os festejos de rei congo, interpretando os símbolos usados para a construção de uma nova identidade, afro-brasileira, e ela entender que tradições africanas estavam sendo rearranjadas e estavam ganhando novos significados, mas permaneciam essencialmente africanas.

No debate aqui proposto, inserido numa história atlântica da diáspora africana e da análise de sociedades formadas a partir o tráfico de escravos e da exploração do trabalho de africanos escravizados, todos concordam com a importância de se entender as conexões entre Brasil, Portugal e as regiões do Congo e de Angola. Mas como ao abordar o catolicismo negro no Brasil os norte-americanos conhecem melhor as realidades africanas, enxergam-na em todos os lugares, enquanto os brasileiros apenas começam a abrir os olhos para a necessidade de entendê-las para melhor analisar os processos de miscigenação cultural ocorridos no Brasil. Para a consolidação de uma produção historiográfica que analise a diáspora africana de forma mais consistente e considerando todos os lugares e culturas envolvidos, os norte-americanos precisam conhecer melhor o contexto brasileiro no qual se inserem as comunidades negras para entender de maneira mais completa as formações culturais e organizações sociais novas, e os brasileiros precisam se dedicar mais ao estudo da história e das culturas africanas, abrindo assim novas perspectivas de compreensão das manifestações afro-americanas.

\section{Referências Bibliográficas}

AGUIAR, Marcos Magalhães de. "Vila Rica dos confrades. A sociabilidade confrarial entre negros e mulatos no século XVIII.” Dissertação de mestrado, Departamento de História - FFLCH/USP, 1993. 
ALVES, Ana Maria. As entradas régias portuguesas. Uma visão de conjunto. Lisboa: Livros Horizonte Ltda, s/d.

ANDRADE, Carlos Drummond de. "Rosário dos homens pretos", Poesia completa e prosa. Rio de Janeiro: Companhia José Aguilar Editora, 1973.

ANDRADE, Mário de. "Os congos”, Danças dramáticas do Brasil. Belo Horizonte: Editora Itatiaia, Brasília: Instituto Nacional do Livro, 1982.

BARLÉUS, Gaspar. História dos feitos recentemente praticados durante oito anos no Brasil e noutras partes sob o governo do ilustríssimo João Maurício, conde de Nassau (1647). Tradução e anotações de Cláudio Brandão. Rio de Janeiro: Serviço Gráfico do Ministério da Educação, 1940.

BROADHEAD, Susan Herlin. "Beyond decline: the Kingdom of the Kongo in the eighteenth and nineteenth centuries", International Journal of African Historical Studies, 12, 1979, pp. 615-650.

CASTAGNA, Paulo Augusto. "Fontes bibliográficas para a pesquisa da prática musical no Brasil nos séculos XVI e XVII. Dissertação de Mestrado, Escola de Comunicações e Artes, Universidade de São Paulo, São Paulo, 1991.

CASTELNAU, Francis. Expedição às regiões centrais da América do Sul. Tradução Olivério M. de Oliveira Pinto. São Paulo: Companhia Editora Nacional, 1949.

COSTA, Rita Gomes. A corte dos reis de Portugal no final da Idade Média. Lisboa: Difel, 1995.

HERLIN, Susan J. "Brazil and the Commercialization of Kongo, 1840-1870", Enslaving Connections. Changing Cultures of Africa and Brazil During the Era of Slavery, edited by José C. Curto and Paul E. Lovejoy. New York: Humanity Books, 2004.

HEYWOOD, Linda M. “As conexões culturais angolano-luso-brasileiras”, Entre Áfricas e Brasis, organizado por Selma Pantoja. São Paulo: Marco Zero / Paralelo 15, 2001.

KARASCH, Mary. Slave Life in Rio de Janeiro 1808-1850. Princeton: Princeton University Press, 1987.

KIDDY, Elizabeth W. "Brotherhoods of Our Lady of the Rosary of the Blacks: Community and Devotion in Minas Gerais, Brazil." UMI Dissertation Information Service, Albuquerque: The University of New Mexico, 1998.

"Who is the King of Congo? A New Look at African and Afro-Brazilian Kings in Brazil", Central Africans and Cultural Transformations in the American Diaspora, edited by Linda M. Heywood. Cambridge: Cambridge University Press, 2002. 
KOSTER, Henry. Viagens ao nordeste do Brasil. Tradução e notas de Luis da Câmara Cascudo. São Paulo: Companhia Editora Nacional, 1942.

LARA, Silvia. "Significados cruzados: as embaixadas de congos na Bahia setecentista", Carnavais e outras $f(r)$ estas, organizado por Maria Clementina Pereira Cunha. Campinas: Cecult / Editora Unicamp, 2001.

Fragmentos Setecentistas: escravidão, cultura e poder na América portuguesa. Tese de Livre-Docência, Departamento de História, IFCH, Unicamp, Campinas, 2004.

MACCORD, Marcelo. “O Rosário dos Homens Pretos de Santo Antonio: alianças e conflitos na história social do Recife, 1848-1873”. Dissertação de Mestrado, Departamento de História, UNICAMP, Campinas, 2001.

MINTZ and PRICE, Sidney and Richard. The Birth of African-American Culture. An Anthropological Perspective, Boston, Beacon Press, 1992 (first edited 1976).

MONTECÚCCOLO, João António Cavazzi de. Descrição histórica dos três reinos do Congo, Matamba e Angola. Tradução, notas e índice do Padre Graciano Maria Leguzzano. Lisboa: Junta de Investigação do Ultramar, 1965.

MORAES FILHO, Mello. Festas e tradições populares do Brasil, $3^{\mathrm{a}}$ edição. Rio de Janeiro: F.Briguiet \& Cia. Editores, 1946.

MULVEY, Patrícia Ann. "The Black Lay Brotherhoods of Colonial Brazil: a history”. UMI Dissertation Information Service, New York: City University of New York, Ph.D., 1976.

OLIVEIRA, Anderson José Machado de. "Devoção e Caridade. Irmandades religiosas no Rio de Janeiro imperial (1840-1889).” Dissertação de mestrado, Departamento de História, UFF, Niterói, 1995.

PRICE, Richard. Alabi's World. Baltimore: The Johns Hopkins University Press, 1990.

QUINTÃO, Antonia Aparecida. Lá vem meu parente. As irmandades de pretos e pardos no Rio de Janeiro e em Pernambuco (século XVIII). São Paulo: Anablume/Fapesp, 2002.

RADULET, Carmem. O cronista Rui de Pina e a "Relação do Reino do Congo". Lisboa: Imprensa Nacional, Casa da Moeda, 1992.

REGINALDO, Lucilene. "Os Rosários dos Angolas: Irmandades negras, experiências escravas e identidades africanas na Bahia setecentista". Tese de Doutorado, Departamento de História, Unicamp, 2005. 
REIS, João José. A morte é uma festa. Ritos fúnebres e revolta popular no Brasil do século XIX. São Paulo: Companhia das Letras, 1991.

SCARANO, Julita. Devoção e escravidão. A Irmandade de Nossa Senhora do Rosário dos Pretos no Distrito Diamantino no século XVIII. $2^{\mathrm{a}}$ edição, São Paulo: Companhia Editora Nacional, 1978.

SLENES, Robert. “'Malungu ngoma vem!' África coberta e descoberta no Brasil”. Revista USP, n.12, dez/jan/fev 1991-1992, pp.48-67.

Na senzala uma flor: as esperanças e as recordações na formação da família escrava - Brasil sudeste, século XIX, Rio de Janeiro, Nova Fronteira, 1999.

SOARES, Mariza de Carvalho. Devotos da Cor: identidade étnica, religiosidade e escravidão no Rio de Janeiro, século XVIII. Rio de Janeiro: Civilização Brasileira, 2000.

SOUZA, Marina de Mello e. Reis negros no Brasil escravista. História da festa de coroação de rei congo, Belo Horizonte, Editora UFMG, 2002.

SPIX e MARTIUS, J.B. Von e C.F.P. Von. Viagem pelo Brasil. Rio de Janeiro: Imprensa Nacional, 1938.

SWEET, James H. Recreating África. Culture, Kinship, and Religion in the African-Portuguese World, 1441-1770. Chapel Hill: The University of North Carolina Press, 2003.

THORNTON, John K. África and Africans in the Making of the Atlantic World, 1400-1680. Cambridge: Cambridge University Press, 1992.

. "On the trail of voodoo: African Christianity in Africa and the Americas", The Americas, 55, jan. 1988, pp. 261- 278.

"Early Kongo-Portuguese relations: a new interpretation". History in Africa. A Journal of Method. Massachusetts: Brandeis University, African Studies Association, v.8, 1981, p. 183-204.

"The Development of an African Catholic Church in the Kingdom of Kongo, 1491-1750”, Journal of African History, 25, 1984, pp. 147-167.

TINHORÃO, José Ramos. Os sons negros no Brasil. Cantos, danças, folguedos: origens. São Paulo: Art Editora, 1988.

Os pretos em Portugal. Uma presença silenciosa. Lisboa: Editorial Caminho, 1988. 